\title{
Detection of Shigella flexneri DNA by ICP-MS Based on Oligonucleotide Hybridization and Labeling of Gold Nanoparticles
}

\author{
Xiuji Wang ${ }^{\mathrm{a}, \mathrm{b}}$, Lanlan Jin ${ }^{\mathrm{a}}$, Wei Guo ${ }^{\mathrm{a}}$, Liuqin Huang ${ }^{\mathrm{a}}$, and Shenghong $\mathrm{Hu}^{\mathrm{a}, *}$ \\ ${ }^{a}$ State Key Laboratory of Biogeology and Environmental Geology, School of Earth Sciences, \\ China University of Geosciences, Wuhan, 430074, P.R. China \\ ${ }^{b}$ Center of Analysis, Guangdong Medical University, Dongguan, 523808, P.R. China
}

\section{INTRODUCTION}

The sensitive detection of DNA is very important in the fields of disease diagnosis, food safety, and environmental monitoring because the genus of bacteria, viruses, and other microorganisms contribute to human diseases. Various molecular methods based on nucleic acid technologies $(1,2)$ have been developed in which sequence-specific DNA oligonucleotides (DNA probes) are used directly in hybridization assays or as primers in amplification reactions to determine the specific target DNA related to pathogenic microorganisms. Polymerase chain reaction (PCR) based on the design of primers, especially real-time PCR, has been developed for DNA quantification and has shown high sensitivity and specificity because of amplification (3-5). However, the complicated design of primers has unavoidably limited the application of this kind of method (6). The sequence-selective DNA detection methods based on hybridization assays rely on thermolecular recognition abilities of the DNA probes that hybridize with their complementary sequences. Target nucleic acids are quantified on the basis of the chemical nature of tags attached to DNA probes. Commonly, DNA probes are labeled frequently with radioactive agents $(7,8)$, fluorescent tags $(9,10)$, and chemiluminescence reagents $(10,11)$.

However, some disadvantages, such as safety concerns and disposal problems of radioactive agents, sophisticated synthesis and

*Corresponding author.

E-mail: sbbu@cug.edu.cn

\section{ABSTRACT}

A simple and sensitive detection method to target DNA of Shigella flexneri was developed by quantification of gold nanoparticles (AuNPs) using inductively coupled plasma mass spectrometry (ICP-MS). A sandwich hybridization assay was established to identify the target DNA using biotinylated capture probes and AuNP-labeled reporter probes in microfuge tubes. The hybridized products were immobilized on microplates via biotin-streptavidin affinity, and subsequently separated with excess nonhybridized probes by washing. $\mathrm{Au}$, originating from the hybridized compounds, was detected by ICP-MS. Good linearity was obtained between the concentration of the target DNA and ${ }^{197} \mathrm{Au}$ signal intensity. The limit of detection (LOD, 3 $\sigma$ ) for the target single-stranded DNA (ssDNA) and the simulated target double-stranded DNA (dsDNA) was calculated as $0.39 \mathrm{pM}$ and $39.17 \mathrm{pM}$. The relative standard deviation (RSD, $\mathrm{n}=3$ ) for $10 \mathrm{pM}$ target ssDNA was found to be $5.8 \%$. The advantages of the proposed method include convenient separation of the hybridization compounds by the biotin-streptavidin system, ease of acquiring reporter probes labeled with AuNPs, and high sensitivity as a DNA assay.

spectral overlap of fluorescent tags, significantly limit their application in DNA quantification.

Recently, inductively coupled plasma mass spectrometry (ICP-MS) based on element tag and hybridization has been used as a comple- mentary technique for the targeted analysis of nucleic acids. In the hybridization assays, the capture probes and the reporter probes labeled with element tags are specifically complementary to the target DNA sequence. After the hybridization products are anchored to the surface of magnetic beads or microplates by capture probes, elements from the reporter probes bound to the hybridization products can be quantified by ICP-MS. Two kinds of elements, lanthanide chelates or metal nanoparticles (gold or silver), are commonly used as tags to label biomolecules and the specific activities of biomolecules can be retained after modification. Lanthanide elements can be tagged to biomolecules using the same strategy because of their similar properties, which favors multiplex analysis $(12,13)$. Nanoparticles are another useful elemental tag for their easy preparation and the enhanced signal from nanoparticles containing numerous metal atoms (14-16). Gold nanoparticle-based probes have been used in the determination of DNA. Han et al. (17) presented an effective and ultrasensitive method for a one-step homogeneous DNA assay using singlenanoparticle detection by ICP-MS. Multiplex quantification of DNA targets associated with clinical diseases [human immunodeficiency virus (HIV), hepatitis A virus (HAV), and Hepatitis B virus (HBV)] were reported by labeling the probes with different NPs (Au NPs, Ag NPs, and Pt NPs) and detecting hybridizations using single-particle (SP) ICP-MS (18). In conclusion, methods based on ICP-MS for the determination of nucleic acids cannot only achieve multiplex analysis 
easily, but also quantify lower abundance DNA targets without PCR amplification because of its low detection limit for metal elements. This kind of method provides a more precise and sensitive signal of the mass-to-charge ratios from the labeled element (especially nanoparticles) of the DNA probe and alleviates the time-consuming and labor-intensive work $(6,19)$.

Infections caused by Shigella flexneri are important agents of diarrhea and dysentery (20-22). In this study, we present a new approach to quantify a 28-base conserved DNA sequence of Shigella flexneri using a hybridization assay combined with ICP-MS as the detection technique. The synthesized specific target DNA associating with the Shigella flexneri was identified by the reporter probes labeled with AuNPs and the capture probes in a sandwich hybridization assay. The intensities of ${ }^{197} \mathrm{Au}$ were obtained using ICP-MS after the hybrid complexes were separated by the biotin-streptavidin affinity reaction and dissolved in $5 \% \mathrm{HNO}_{3}$. This is the first report of ICP-MS used to determine the specific genomic sequence of Shigella flexneri. Optimization of the hybridization assay, concentration of streptavidin coated on the microwell, specificity of hybridization, and the analytical performance are also described.

\section{EXPERIMENTAL}

\section{Instrumentation}

A 7700x series ICP-MS (Agilent Technologies Inc., Tokyo, Japan) was used in detecting the ${ }^{197} \mathrm{Au}$ signal. A solution of $100 \mathrm{ng} \mathrm{g}^{-1}{ }^{103} \mathrm{Rh}$ internal standard was spiked into all samples. The optimized parameters for ICP-MS are listed in Table I. A JEM-2010 transmission electron microscope (TEM) (Philips CM12 TEM/STEM, The Netherlands) was used to characterize the AuNPs. A UV-1750 spectrophotometer
(Shimadzu, Suzhou, P.R. China) was used for recording the ultravioletvisual (UV-Vis) absorption spectrum of the AuNPs and the reporter probes labeled with the AuNPs in a $1-\mathrm{cm}$ quartz cell.

\section{Reagents and Materials}

All oligonucleotides and DNA probes were synthesized by Shanghai Sangon Biotech Co., Ltd. (Shanghai, P.R. China). The sequences of the oligonucleotides used in this study are listed in Table II (see page 48) where Sequence 3 was target ssDNA, Sequence 7 was the complementary strand to target ssDNA, and others were mismatched oligonucleotides. All of these were dissolved in ultrapure $\mathrm{H}_{2} \mathrm{O}$. The capture probe (Sequence 1) and the reporter probe, functionalized with the thiol groups $(-\mathrm{SH})$ at the 3'-end (Sequence 2), was diluted in the TE buffer.

The streptavidin was obtained from Shanghai Sangon Biotech Co., Ltd. Bovine serum albumin (BSA) was purchased from Wuhan Chu Cheng Zheng Mao Science and Technology Engineering Co. Ltd. (Wuhan, P.R. China). Chloroauric acid $\left(\mathrm{HAuCl}_{4} \bullet 4 \mathrm{H}_{2} \mathrm{O}\right)$ for AuNPs preparation was acquired from Sinopharm Chemical Reagent Co. Ltd. (Shanghai, P.R. China). Tween

TABLE I Operating Parameters for ICP-MS

\begin{tabular}{lr}
\hline Parameters & Description \\
\hline ICP RF power & $1450 \mathrm{~W}$ \\
Plasma gas flow rate & $15 \mathrm{~L} \mathrm{~min}^{-1}$ \\
Carrier gas flow rate & $1.02 \mathrm{~L} \mathrm{~min}^{-1}$ \\
Auxiliary gas flow rate & $1.0 \mathrm{~L} \mathrm{~min}^{-1}$ \\
Sample uptake rate & $0.35 \mathrm{~mL} \mathrm{~min}^{-1}$ \\
Integration time & $1.5 \mathrm{~s}$ \\
Sampling depth & $8 \mathrm{~mm}$ \\
Replicates & 3 \\
Isotope used & ${ }^{197} \mathrm{Au}$ \\
Internal standard used & ${ }^{103} \mathrm{Rh}$ \\
\hline
\end{tabular}

20 was purchased from SigmaAldrich Chemical Co. (St. Louis, MO, USA).

The buffers and solutions used were (a) phosphate buffered saline (PBS, pH 7.4); (b) coating buffer: $\left(\mathrm{Na}_{2} \mathrm{CO}_{3}, \mathrm{NaHCO}_{3}, \mathrm{pH}\right.$ 9.6); (c) blocking buffer: $5 \%$ BSA in PBS; (d) hybridizing buffer (PBS, pH 7.8); (e) washing solution (PBS, Tween $200.04 \%, \mathrm{pH} 7.4$ ); and (f) TE buffer: $10 \mathrm{mM}$ Tris-HCl, $1 \mathrm{mM}$ EDTA, pH 8.0. All buffers were prepared using ultra-pure water (18.2 $\left.\mathrm{M} \Omega \mathrm{cm}^{-1}\right)$.

\section{Preparation of Reporter Probes Modified by AuNPs}

Gold particles, approximately $15 \mathrm{~nm}$,. were synthesized according to previously published procedures $(23,24)$. For subsequent experiments, the solution was diluted to $50 \mathrm{~mL}$ with ultrapure water. The average particle diameter of about $15 \mathrm{~nm}$ was measured using TEM, which is shown in Figure 1(a). The final concentration of gold particles could be estimated using Beer's Law by using the extinction coefficient of about $10^{8} \mathrm{M}^{-1} \mathrm{~cm}^{-1}$ for 15-nm diameter particles at around $520 \mathrm{~nm}(24)$.

The preparation of reporter probes modified by AuNPs was performed according to the literature $(18,25)$. The DNA probes, modified with AuNPs, were adjusted to a stock concentration of $0.2 \mathrm{M}$ sodium and $0.1 \mathrm{M}$ phosphate buffer $(\mathrm{pH}=7.0)$ for subsequent use. The UV-Vis spectra of the $15 \mathrm{~nm}$ AuNPs and the AuNPs conjugated with reporter probes are shown in Figure 1(b). The results showed a 5-nm red-shift. This was caused by the increase in size of the AuNPs when conjugated to the ssDNA, thus confirming the attachment of the ssDNA to the NPs (26).

\section{Hybridization Assay}

Before the hybridization assay, micro-well plates were coated with 
streptavidin. One hundred microliters of streptavidin (diluted 100x with coating buffer) was added into each well and incubated at $4{ }^{\circ} \mathrm{C}$ overnight. After washing twice with PBST, the coated micro-well plate was blocked using a blocking buffer at $37^{\circ} \mathrm{C}$ for 2 hours. The schematic diagram of the hybridization assay is shown in Figure 2. An artificial 28-base oligonucleotide (Sequence 3) was used in its singlestranded form as the specific target DNA which was a conserved sequence of Shigella flexneri. Initially, a $10-\mu \mathrm{L}$ solution of target ssDNA (Sequence 3), $10 \mu \mathrm{L}$ of biotinylated capture DNA (Sequence 1), and $20 \mu \mathrm{L}$ of hybridizing buffer were mixed in a microfuge tube and hybridized for 20 minutes at room temperature. Then, $5 \mu \mathrm{L}$ of the reporter probes (Sequence 2) labeled with AuNPs

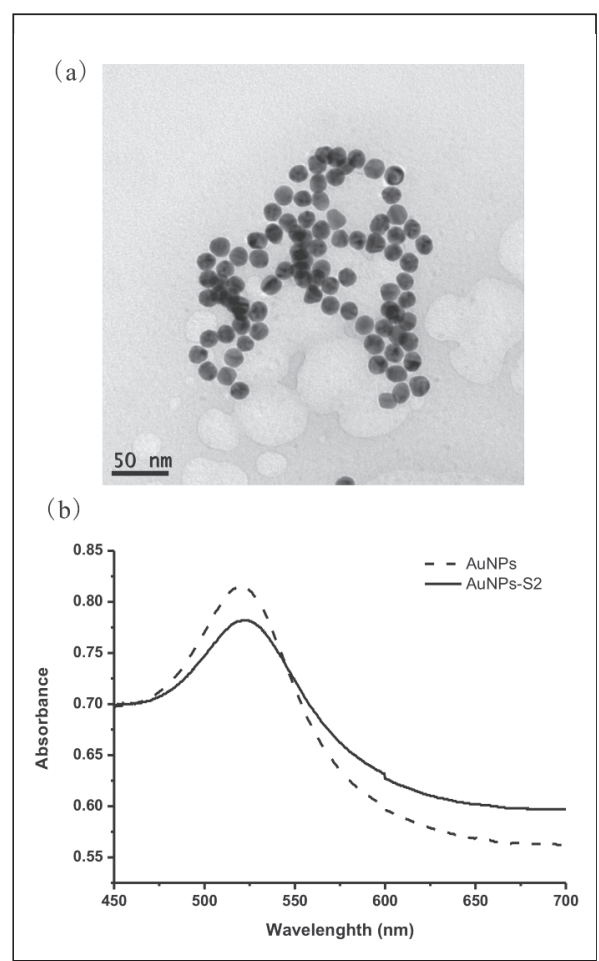

Fig. 1 ( $a$ and b). (a) TEM image of 15-nm gold nanoparticles (AuNPs) and (b) Ultraviolet-visual spectrum of synthesized AuNPs, and AuNPs conjugated with reporter probes (S2, Sequence 2). was added into each tube and incubated for another 20 minutes at room temperature. The hybridized products were transferred into the coated microplates to be incubated at $37^{\circ} \mathrm{C}$ for 30 minutes before being washed three times by PBST and twice by ultra-pure water. A 5\% (v/v) $\mathrm{HNO}_{3}$ solution was added to release AuNPs from the hybridized complexes, and the ${ }^{197} \mathrm{Au}$ intensities were determined using ICP-MS. External calibration was used for the quantitative determination of the target ssDNA.

Simulated target dsDNA sequences were obtained by mixing the equimolar ratio of Sequence 3 and Sequence 7 in water (27). The solution was first boiled at $95^{\circ} \mathrm{C}$ for 5 minutes to melt the duplex and then cooled slowly to room temperature. A 10-microliter solution of capture DNA probes (Sequence 1), $10 \mu \mathrm{L}$ of reporter probes functionalized with AuNPs, and $20 \mu \mathrm{L}$ hybridization buffer were added to the dsDNA solution and incubated for 30 minutes. Subsequent steps followed the same procedure as that for the target ssDNA. All experiments were performed in triplicate.

\section{RESULTS AND DISCUSSION}

\section{Optimization of the Hybridiza- tion Assay Conditions}

A sandwich hybridization is presented in the schematic diagram (Figure 2). First, the excess capture DNA probes were reacted with the target ssDNA in hybridization 1. Then, the hybridized complexes were reacted with the reporter probes labeled with AuNPs in hybridization 2 . The sensitivity of this assay is dependent on the number of hybridized complexes that are bound to the microplates via biotin-streptavidin affinity. More sites would be occupied by excessfree biotin-labeled capture probes, and fewer hybrids complexed with capture probes would be immobilized by the microplate, which might result in poor detection sensitivity and reproducibility. In addition, an excess of reporter probes labeled with AuNPs in the reaction system is essential for hybridization; however, a high concentration of reporter probes would lead to high background intensity (28). Therefore, the hybridization conditions should be optimized to increase the detection sensitivity.

A series of capture probes (Sequence 1) were investigated to identify an appropriate concentra-

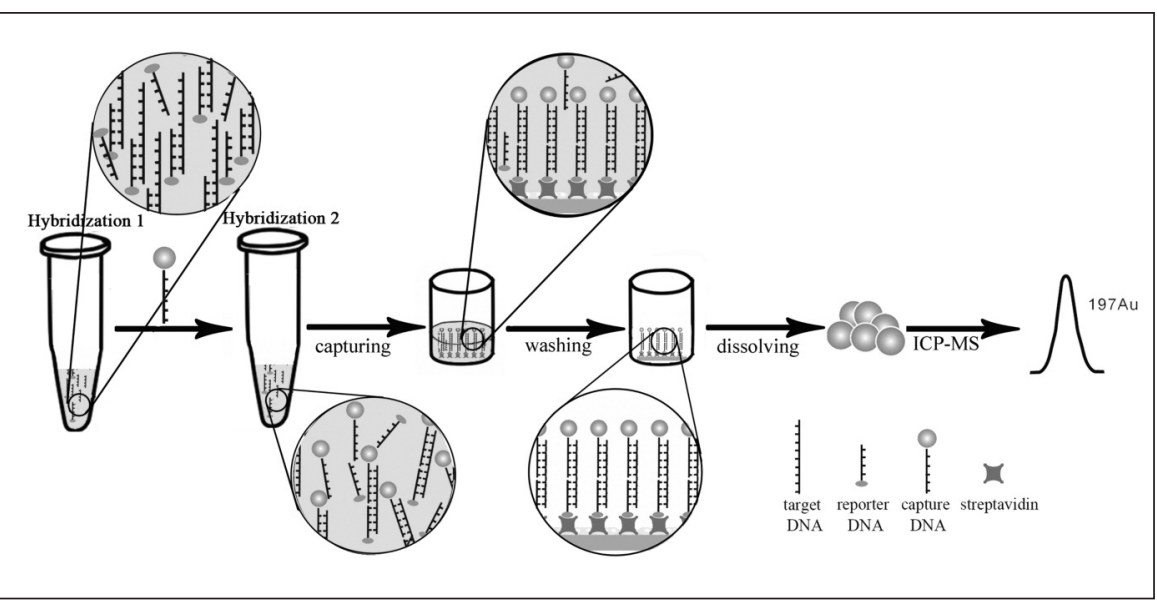

Fig. 2. Schematic diagram of the assay to detect DNA based on oligonucleotides bybridization and the quantification of gold nanoparticles (AuNPs) by ICP-MS. 
tion when the target SsDNA was $10 \mathrm{pM}$ and the dilution ratio of the reporter probes labeled with AuNPs was 1:10. The Au signal intensities were acquired when the concentration of Sequence 1 changed from 0.01 to $5 \mathrm{nM}$. As shown in Figure 3(a), the highest ratio of Au signal/background intensity appeared when the concentration was $0.5 \mathrm{nM}$. Therefore, $0.5 \mathrm{nM}$ of Sequence 1 was used for subsequent hybridizations.

The dilution ratio of reporter probes labeled with AuNPs was optimized from 1:2 to 1:50 with a target ssDNA concentration of
$10 \mathrm{pM}$. Figure 3(b) shows that a favorable ${ }^{197} \mathrm{Au}$ signal/background ratio was obtained until the dilution ratio of the probes was reduced 1:20. According to the results, a higher dilution of the Au NPs-modified probes when hybridizing with the target DNA might result in poorer detection sensitivity, while a lower dilution ratio would probably result in a higher background and poorer detection sensitivity. Consequently, a 1:20 dilution of AuNPsmodified probes was selected to be applied in the hybridization assay considering both the effect of detection sensitivity and background.

\section{Atomic Mpectroscopy \\ 1 Vol. 38(3), May/June 2017}

\section{Effect of Streptavidin Concen- tration on Au Signal/Back- ground Ratio}

A convenient system for separating hybridization complexes from other reagents was carried out by microplates coated with streptavidin. In this system, streptavidin was used to fix hybridization by the capture DNA because streptavidin binding to biotin is specific enough to ensure that the binding is directed only to the target of interest (29). The concentration of streptavidin coated on the microplate was a key factor for the Au signal/background intensity ratio. The dilution ratio of streptavidin (1 $\mathrm{mg} \mathrm{mL}^{-1}$ ) from 1:50 to 1:200 was investigated when the target ssDNA was in the range from 0.5 to $50 \mathrm{pM}$. Figure 4 indicates that the same results were obtained with a dilution ratio of $1: 50$ and $1: 100$. The latter was appropriate for further studies because less streptavidin was consumed. (a)

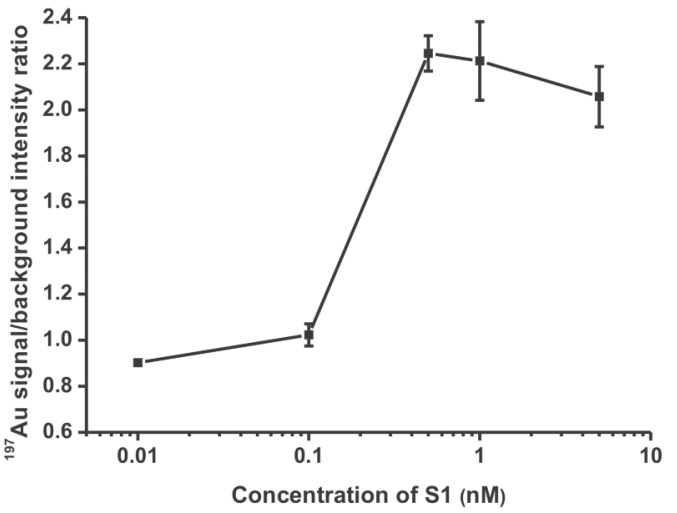

(b)

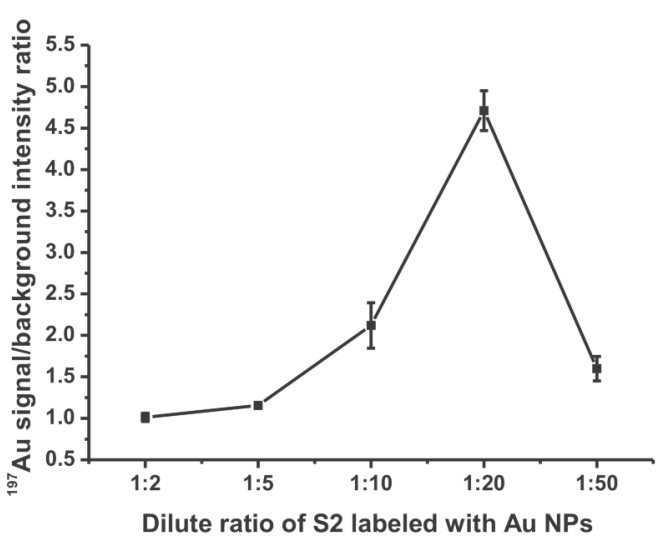

Fig. 3 ( $a$ and b). Effect of (a) concentration of capture DNA probes (S1, Sequence 1) and (b) dilution ratio of reporter probes (S2, Sequence 2) on the Au signal/background ratio. Target ssDNA was at a concentration of $10 \mathrm{pM}$.

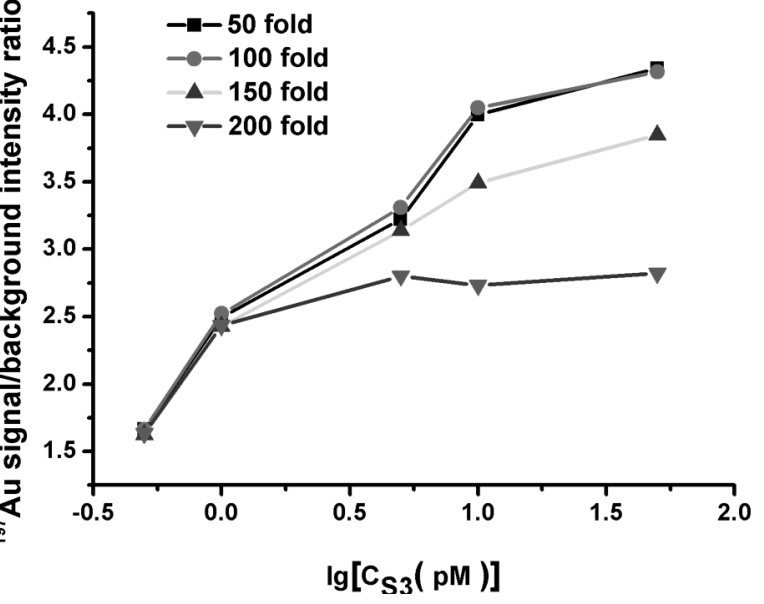

Fig. 4. Effects of concentration of streptavidin on the ${ }^{197} \mathrm{Au}$ signal/background ratio. 


\section{Specificity of Hybridization}

In the detection of Shigella flexneri in environmental or clinical samples, thousands of other mismatched and random length DNA fragments are present in the DNA lysate together with the target DNA. To verify specificity of hybridization, three mismatched ssDNA sequences were also tested using the same experimental procedure (Figure 5). Sequence 4 had a 1-base mismatch oligonucleotide, and Sequence 5 had a 5-base mismatch oligonucleotide, respectively, while Sequence 6 was a random oligonucleotide sequence (Table II). Compared to other mismatched and the random DNA sequences, a higher intensity of ${ }^{197} \mathrm{Au}$ from the completely matched target DNA (Sequence 3) was observed, which indicated that the target DNA could be distinguished easily in the presence of other irrelevant sequences using this method.

\section{Analytical Performance}

This method was based on the indirect detection of synthetic target DNA sequences of Shigella flexneri in a proof-of-principle experiment. The artificial target ssDNA was studied first. Under the optimized conditions, a series of concentrations of the target ssDNA sequence, from 0.5 to $50 \mathrm{pM}$, was

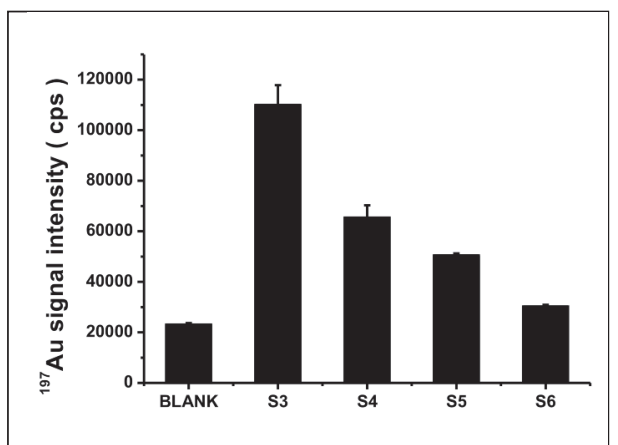

Fig. 5. Specificity for the determination of target ssDNA (S3, Sequence 3) using the proposed bybridization (S4, Sequence 4; S5, Sequence 5; S6, Sequence 6). All oligonucleotides were used at a concentration of 1 pM.

TABLE II

Sequences of Oligonucleotides Used in DNA Hybridization

\begin{tabular}{ll}
\hline Name & Sequence $\left(5^{\prime}-3^{\prime}\right)$ \\
\hline Sequence 1 & Biotin-gcagtCCGAAGTTAAGCTAC \\
Sequence 2 & CTACTTCTTTTAC-(CH2) 6 -SH \\
Sequence 3 & GTAAAAGAAGTAGGTAGCTTAACTTCGG \\
Sequence 4 & GTAAAAGCAGTAGGTAGCTTAACTTCGG \\
Sequence 5 & GTGGGAGAAGCCGGTAGCTTAACTTCGG \\
Sequence 6 & ACATCTGCATTTCCGTTAAAGTCCCGTTCGTAAATGCTGTT- \\
Sequence 7 & CCGAAGTTAAGCTACCTACTTCTTTTAC \\
\hline
\end{tabular}

tested in the quantitative assay. As shown in Figure 6(a), the signal intensity of ${ }^{197} \mathrm{Au}$ correlated linearly with the logarithm of the target DNA concentration (correlation coefficient of $\left.\mathrm{r}^{2}=0.9715\right)$. The precision for concentration of the target DNA at $10 \mathrm{pM}$ with three replicate measurements was $5.8 \%$ (RSD). The detection limit (LOD, $3 \sigma$ ) of the proposed method for the 28-base synthesized target ssDNA was calculated to be $0.39 \mathrm{pM}$, where the $\sigma$ is the standard deviation of repetitive measurements of the assay solution blank.

DNA is not readily available to bind complementary sequences in its native form because it is usually present as a double-strand molecule in organisms. Thus, it is necessary to convert dsDNA to ssDNA by melting the duplex before hybridization. In this process, the probes and the degraded complementary sequences were competitively combined with the target ssDNA (30). Compared with the spiked target ssDNA, quantifying the dsDNA required the addition of excess reporter DNA probes (Sequence 2 labeled with AuNPs) and capture DNA probes. The excess DNA strands could be removed by washing, which reduced the background effectively.
Simulated dsDNA in different concentrations was also determined by the proposed method. The calibration curve of Figure 6(b) shows a good correlation between the ${ }^{197} \mathrm{Au}$ signal and the logarithm of the concentration of the target dsDNA (correlation coefficient of $\left.\mathrm{r}^{2}=0.9659\right)$ in the range from $10^{2}$ $\mathrm{pM}$ to $10^{4} \mathrm{pM}$. The precision for the concentration of the target DNA at $10^{3} \mathrm{pM}$ with three replicate measurements was $5.5 \%$ (RSD). The detection limit (LOD, 3 $\sigma$ ) was about $39.17 \mathrm{pM}$.

\section{Comparing the LODs of Various DNA Hybridization Assays}

The sensitivity could be enhanced using AuNP tags instead of metal ions for the nanoparticles containing numerous metal atoms (28). Moreover, streptavidin has four binding sites for biotin, making it possible to couple more tags per streptavidin molecule which can further increase the sensitivity of the assay. The LOD of the developed method for the synthesized 28-base ssDNA target was compared with some values derived from the literature $(6,18$, 19, 31) for direct DNA hybridization assays with AuNPs tags. As shown in Table III, the LOD obtained by the present method is better than those of others. 


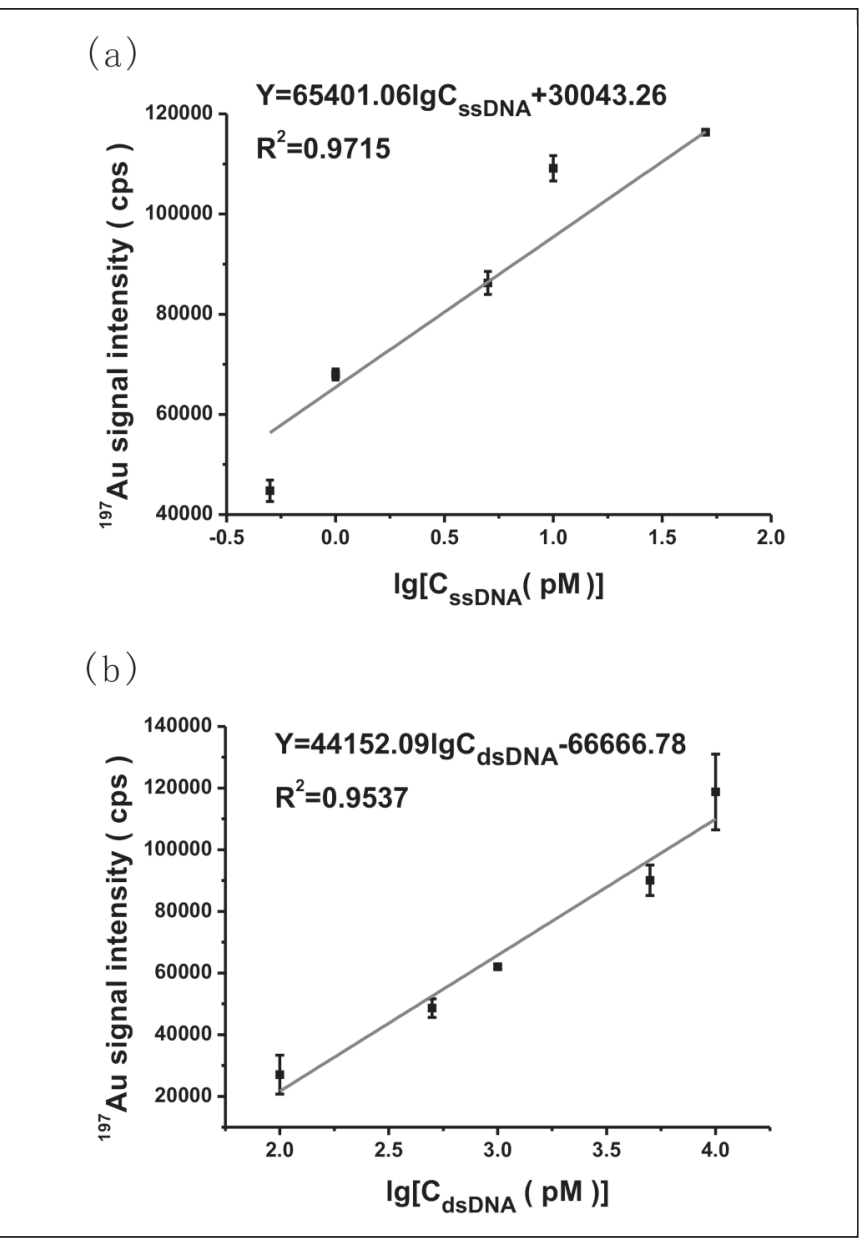

Fig. 6 ( $a$ and $b$ ). Correlation between the ${ }^{197}$ Au signal intensity and the logarithm of (a) target ssDNA (the concentration varied from 0.5 to $50 \mathrm{pM}$ ) and (b) simulated dsDNA (the concentration varied from $10^{2}$ to $10^{4} \mathrm{pM}$ ). $100 \mathrm{ng} \mathrm{g}^{-1}{ }^{103} \mathrm{Rh}$ was spiked into the solution as an internal standard.

TABLE III

Comparison of Various DNA Assays Based on the AuNPs Labels

\begin{tabular}{llll}
\hline $\begin{array}{l}\text { Detection } \\
\text { Methods }\end{array}$ & Dynamic Range & LOD & References \\
\hline Colorimetry & $0.25-50 \mathrm{nM}$ & $50 \mathrm{pM}$ & $(31)$ \\
ICP-MS & $1-100 \mathrm{pM}$ & $1 \mathrm{pM}$ & $(18)$ \\
ICP-AES & $350-3.5 \times 10^{6} \mathrm{pM}$ & $350 \mathrm{pM}$ & $(19)$ \\
ETV-AAS & $10-200 \mathrm{pM}$ & $3 \mathrm{pM}$ & $(6)$ \\
ICP-MS & $0.5-50 \mathrm{pM}$ & $0.39 \mathrm{pM}$ & This work \\
\hline
\end{tabular}

\section{Atomic Mpectroscopy \\ 1 Vol. 38(3), May/June 2017}

\section{CONCLUSION}

A valid method based on a DNA hybridization assay and AuNPs labeling for the accurate ICP-MS determination of specific target DNA related to Shigella flexneri was studied. Highly efficient hybridization was verified by the signal intensity from the hybridized complexes. The convenient separation process for hybridized complexes was accomplished by the effective and low-cost system of biotin-streptavidin affinity. This study indicates that ICP-MS coupled with a DNA hybridization assay is a promising method for the sensitive detection of specific DNA of Shigella flexneri and provides new insights into the quantification of low abundance nucleic acids in biological samples without amplification of PCR. It has great potential for the determination of various bacterial pathogens by ICP-MSbased multiplex assay with multiplex NP tags using oligonucleotide hybridization strategy in the future.

\section{ACKNOWLEDGMENT}

This work was supported by the China Scholarship Council, the National Nature Science Foundation of China (No. 41521001 and No. 21207120), the Ministry of Science and Technology of China (No. 2014DFA20720), and the Research Program of the State Key Laboratory of Biogeology and Environmental Geology of China.

Received March 20, 2017.

\section{REFERENCES}

1 J. Shendure, and H.L. Ji, Nat. Biotechnol. 26, 1135 (2008).

2 D.J. Lockhart, H.L. Dong, M.C. Byrne, M.T. Follettie, M.V. Gallo, M.S. Chee, M. Mittmann, C.W. Wang, M. Kobayashi, H. Horton, and E.L. Brown, Nat. Biotechnol. 14, 1675 (1996). 
3 M.A. Nadkarni, F.E. Martin, N.A. Jacques, and N. Hunter, Microbiology-(UK) 148, 257 (2002).

4 M.J. Espy, J.R. Uhl, L.M. Sloan, S.P. Buckwalter, M.F. Jones, E.A. Vetter, J.D.C. Yao, N.L. Wengenack, J.E. Rosenblatt, F.R. Cockerill, and T.F. Smith, Clin. Microbiol. Rev. 19, 165 (2006).

5 L. Gutierrez, M. Mauriat, J. Pelloux, C. Bellini, and O.V. Wuytswinkel, Plant Cell 20, 1734 (2008).

6 X.M. Xu, Y. Gao, S.X. Zhang, S.Z. Li, T. Bai, Y. Zhang, X.R. Hu, and R. Liu, Microchem J. 126, 302 (2016).

7 L. Chen, Y. Wang, D.F. Cheng, X.R. Liu, S.P. Dou, G.Z. Liu, D.J. Hnatowich, and M. Rusckowski, Bioorg. Med. Chem. 21, 6523 (2013).

8 M.K. Dewanjee, A.K. Ghafouripour, R.K. Werner, A.N. Serafini, and G.N. Sfakianakis, Bioconj. Chem. 2, 195 (1991).

9 H.A. Bassler, S.J.A. Flood, K.J. Livak, J. Marmaro, R. Knorr, and C.A. Batt, Appl. Environ. Microbiol. 61, 3724 (1995).

10 E. Avanissaghajani, K. Jones, D. Chapman, and C. Brunk, Biotechniques 17, 144 (1994).

11 J. Kwun, S. Yun, L. Park, and J.H. Lee, Talanta 119, 262 (2014).

12 G. Han, S. Zhang, Z. Xing, and X. Zhang, Angew. Chem. Int. Ed. 52, 1466 (2013).

13 Y.C. Luo, X.W. Yan, Y.S. Huang, R.B. Wen, Z.X. Li, L.M. Yang, C.J. Yang, and Q.Q. Wang, Anal. Chem. 85, 9428 (2013).

14 F. Li, Q. Zhao, C.A. Wang, X.F. Lu, X.F. Li, and X.C. Le, Anal. Chem. 82, 3399 (2010).

15 R. Liu, P. Wu, L. Yang, X.D. Hou, and Y. Lv, Mass Spectrom. Rev. 33, 373 (2014).

16 S. Hu, R. Liu, S. Zhang, Z. Huang, Z. Xing, and X. Zhang, J. Am. Soc. Mass. Spectrom. 20, 1096 (2009).

17 G. Han, Z. Xing, Y. Dong, S. Zhang, and $X$. Zhang, Angew. Chem. Int. Ed. 50, 3462 (2011).

18 S.X. Zhang, G.J. Han, Z. Xing, S.C. Zhang, and X.R. Zhang, Anal. Chem. 86, 3541 (2014).
19 L.L. Wu, L.W. Qiu, C.S. Shi, and J. Zhu, Biomacromolecules 8, 2795 (2007).

20 K.L. Kotloff, J.P. Winickoff, B. Ivanoff, J.D. Clemens, D.L. Swerdlow, P.J. Sansonetti, G. Adak, and M. Levine, Bull. W.H.O. 77, 651 (1999).

21 D.M. Deer, and K.A. Lampel, J. Food Prot. 73, 1618 (2010).

22 M.J. Hosseini, and A.R. Kaffashian, Arch. Iran. Med. 13, 413 (2010).

23 G. Frens, Nature Phys. Sc.i 241, 20 (1973).

24 C.C. Huang, Y.F. Huang, Z.H. Cao, W.H. Tan, and H.T. Chang, Anal. Chem. 77, 5735 (2005).

25 R. Elghanian, J.J. Storhoff, R.C. Mucic, R.L. Letsinger, and C.A. Mirkin, Science 277, 1078 (1997).

26 J. Thavanathan, N.M. Huang, and K.L. Thong, Biosensors \& Bioelectronics 55, 91 (2014).

27 K. Brueckner, K. Schwarz, S. Beck, and M.W. Linscheid, Anal. Chem. 86, 585 (2014).

28 Q. He, Z.L. Zhu, L.L. Jin, L. Peng, W. Guo, and S.H. Hu, J. Anal. At. Spectrom. 29, 1477 (2014).

29 P.J. Ginel, J.M. Margarito, J.M. Molleda, R. Lopez, and M. Novales, Res. Vet. Sci. 60, 107 (1996).

30 B.S. Li, L.F. Zhao, C. Zhang, X.H. Hei, F. Li, X.B. Li, J. Shen, Y.Y. Li, Q. Huang, and S.Q. Xu, Anal. Sci. 22, 1367 (2006).

31 X. Mao, H. Xu, Q.X. Zeng, L.W. Zeng, and G.D. Liu, Chem. Commun. 21, 3065 (2009). 